\title{
Ownership and Control Structures A Case Study
}

\author{
Asst. Professor of Business Administration \\ Mico Apostolov, PhD \\ UGD \\ Krste Misirkov b.b. P.O. Box 201 \\ 2000 Stip - Macedonia \\ Tel.: MKD +38977848250 \\ | e-mail: mico.apostolov@ugd.edu.mk | \\ home page: http://www.micoapostolov.com/ \\ | UGD page: http://scholar.ugd.edu.mk/micoapostolov | \\ * Alumnus of Scuola Superiore Sant'Anna (Normale di Pisa), Pisa, Italia \\ * Alumnus of University of California, Berkeley - Haas School of Business, CA, USA \\ * Anciens du Collège d'Europe, Bruges/Natolin
}

\section{Abstract}

This is a study on separation of ownership and control in Southeast Europe, and in particular it is a case study of Macedonia. For structured analysis of this case study we use the World Bank Microdata Library, specifically the Enterprise Surveys which contains firm-level data of a representative sample of economies private sectors.

What we are interested in are the ties of ownership and control and whether such linkages contribute to the development of domestic firms and the overall economy. Corporate governance systems and ownership structures are economic fundamentals which influence economic behavior and corporate performance. Market-oriented corporate systems and network-oriented corporate systems are novelty in much needed enterprise restructuring process due to economic transition.

This paper is a contribution to the research developing the business aspects of the Southeast Europe economy, as there is constant lack of scientific papers that deal with the specific issues of corporate governance and enterprise restructuring.

JEL Classifications: G30, G38, L33, O11, P31

Keywords: Ownership, Control structure, Corporate Governance 